\title{
Open
}

\section{Navigating the research-clinical interface in genomic medicine: analysis from the CSER Consortium}

\author{
Susan M. Wolf, JD ${ }^{1}$, Laura M. Amendola, MS, CGC ${ }^{2}$, Jonathan S. Berg, MD, PhD², \\ Wendy K. Chung, MD, $\mathrm{PhD}^{4}$, Ellen Wright Clayton, MD, JD ${ }^{5}$, Robert C. Green, MD, $\mathrm{MPH}^{6}$, \\ Julie Harris-Wai, $\mathrm{PhD}, \mathrm{MPH}^{7}$, Gail E. Henderson, $\mathrm{PhD}^{8}$, Gail P. Jarvik, MD, $\mathrm{PhD}^{2,9}$, \\ Barbara A. Koenig, PhD ${ }^{10}$, Lisa Soleymani Lehmann, MD, PhD ${ }^{11,12}$, Amy L. McGuire, JD, PhD ${ }^{13}$, \\ Pearl O'Rourke, MD ${ }^{14}$, Carol Somkin, $\mathrm{PhD}^{15}$, Benjamin S. Wilfond, MD ${ }^{16}$ and \\ Wylie Burke, MD, PhD 2,17
}

\begin{abstract}
Purpose: The Clinical Sequencing Exploratory Research (CSER) Consortium encompasses nine National Institutes of Healthfunded $\mathrm{U}$-award projects investigating translation of genomic sequencing into clinical care. Previous literature has distinguished norms and rules governing research versus clinical care. This is the first study to explore how genomics investigators describe and navigate the research-clinical interface.
\end{abstract}

Methods: A CSER working group developed a 22-item survey. All nine U-award projects participated. Descriptive data were tabulated and qualitative analysis of text responses identified themes and characterizations of the research-clinical interface.

Results: Survey responses described how studies approached the research-clinical interface, including in consent practices, recording results, and using a research versus clinical laboratory. Responses revealed four characterizations of the interface: clear separation between research and clinical care, interdigitation of the two with steps to maintain separation, a dynamic interface, and merging of the two. All survey respondents utilized at least two different characterizations. Although research has traditionally been differentiated from clinical care, respondents pointed to factors blurring the distinction and strategies to differentiate the domains.

Conclusion: These results illustrate the difficulty in applying the traditional bifurcation of research versus clinical care to translational models of clinical research, including in genomics. Our results suggest new directions for ethics and oversight.

Genet Med advance online publication 31 August 2017

Key Words: exome sequencing; genome sequencing; research ethics; translational ethics; translational genomics

\section{INTRODUCTION}

Translational genomics straddles the domains of research and clinical care. ${ }^{1}$ Research projects such as those included in the Clinical Sequencing Exploratory Research (CSER) Consortium funded by the National Institutes of Health (NIH) aim to create an evidence base for successful integration of genome and exome sequencing into clinical care. ${ }^{2}$ CSER research projects were funded to "address critical questions about the application of genomic sequencing to clinical care of individual patients." 3 Importantly, the intent of the CSER projects is not discovery but clinical implementation of genome-scale sequencing. Thus, the CSER projects may be uniquely positioned to identify challenges faced at the research-clinical interface.

The CSER projects investigate the clinical utility of sequencing in a range of clinical settings involving both pediatric and adult participants. Most of the studies enroll patients with clinical indications related to cancer, neurodevelopmental disorders, cardiovascular disease, or rare genetic disorders, but CSER projects include an investigation of genomic screening in healthy people and the use of sequencing in carrier testing for individuals planning a pregnancy. Investigators confront a range of issues at the interface between research and clinical care, including

\footnotetext{
${ }^{1}$ Law School; Medical School; Consortium on Law and Values in Health, Environment \& the Life Sciences, University of Minnesota, Minneapolis, Minnesota, USA; ${ }^{2}$ Medical Genetics, Department of Medicine, University of Washington, Seattle, Washington, USA; ${ }^{3}$ Departments of Genetics and Medicine, University of North Carolina at Chapel Hill, Chapel Hill, North Carolina, USA; ${ }^{4}$ Departments of Pediatrics and Medicine, Columbia University, New York, New York, USA; ${ }^{5}$ Center for Biomedical Ethics and Society, Vanderbilt University Medical Center, Nashville, Tennessee, USA; ${ }^{6}$ Genetics, Department of Medicine, Brigham and Women's Hospital, Broad Institute and Harvard Medical School, Boston, Massachusetts, USA; ${ }^{7}$ Institute for Health and Aging, University of California-San Francisco; Division of Research, Kaiser Permanente Northern California, San Francisco, California, USA; ${ }^{8}$ Department of Social Medicine, University of North Carolina at Chapel Hill, Chapel Hill, North Carolina, USA; ${ }^{9}$ Department of Genome Sciences, University of Washington, Seattle, Washington, USA; ${ }^{10}$ Program in Bioethics, Institute for Health and Aging, University of California-San Francisco, San Francisco, California, USA; ${ }^{11}$ Veterans Administration National Center for Ethics in Health Care, Washington, DC, USA; ${ }^{12}$ Harvard University, Cambridge, Massachusetts, USA; ${ }^{13}$ Center for Medical Ethics and Health Policy, Baylor College of Medicine, Houston, Texas, USA; ${ }^{14}$ Human Research Affairs, Partners HealthCare, Boston, Massachusetts, USA; ${ }^{15}$ Division of Research, Kaiser Permanente Northern California, Oakland, California, USA; ${ }^{16}$ Treuman Katz Center for Pediatric Bioethics, Seattle Children's Hospital, Department of Pediatrics, University of Washington, Seattle, Washington, USA; ${ }^{17}$ Department of Bioethics and Humanities, University of Washington, Seattle, Washington, USA. Correspondence: Susan M. Wolf (swolf@umn.edu)
} 
whether to use research or clinical laboratories for sequencing, whether to record results in the research or medical record, what findings to offer back to patient-participants, and what services and follow-up to charge to research budgets or submit for insurance reimbursement. ${ }^{4,5}$

Translational genomics is not alone in raising issues at the interface between research and clinical care; clinical research investigating the effectiveness of a drug or other intervention in affected patients may raise such issues as well. ${ }^{6}$ However, the literature on translational genomics reflects a growing challenge to the traditional view that research and clinical care are distinct activities that should be governed by separate norms and rules. ${ }^{1,7-10}$ Beginning with the Belmont Report ${ }^{11}$ and emergence of regulations governing the conduct of research with human participants, ${ }^{12,13}$ the conventional view has been that there are fundamental differences between research and clinical care, necessitating distinctive ethical frameworks and regulatory oversight. ${ }^{14}$ (See Table 1). Research has been defined by the Common Rule as "a systematic investigation...designed to develop or contribute to generalizable knowledge," through a process that might or might not offer potential benefit to participants, with safeguards provided by institutional review board (IRB) oversight, extensive consent requirements, and limits on acceptable research. In clinical care, on the other hand, clinicians bear a fiduciary duty to act primarily for the benefit of the patient in keeping with established standards of professionalism and ethics. A large literature addresses the potential for confusion regarding the goals of research and clinical care and offers recommendations for maintaining the distinction. ${ }^{15-19}$

The rise of translational research is among the developments that have raised new questions about the viability and future of this dichotomous approach. ${ }^{1,7,9}$ When research is designed to investigate clinical integration of emerging interventions such as genomic sequencing, the goals of advancing generalizable knowledge and benefiting those who undergo sequencing can be closely intertwined. While a literature has begun to emerge on these issues, ${ }^{1,20,21}$ no prior studies have documented how genomics investigators see the relationship of research to clinical care, what challenges they encounter when conducting translational genomics research, and what solutions they are deploying to navigate these issues. We report here perspectives from the nine CSER studies.

\section{MATERIALS AND METHODS}

\section{Survey development}

A working group of the CSER Consortium developed a survey (see Supplementary Material online) consisting mainly of short-answer questions, both closed- and open-ended, to assess factors relevant to the research-clinical interface. Items were based on literature review and solicited experiences of consortium investigators. The survey included 16 specific questions about the respondent's study, including consent procedures; involvement of research and clinical personnel; disclosure of results; where results are recorded (in the medical record, research record, or both); procedures covered by the research budget versus billed to insurers; and legal issues raised in study design or implementation, plus use of a research or CLIA-certified clinical laboratory. Respondents were also asked to answer six general questions eliciting their views on the interface between genomic research and clinical care. They could add additional comments. A draft survey was piloted at one of the 9 CSER sites to assess comprehension and survey completeness, with revision based on feedback.

\section{Survey completion}

Each CSER principal investigator was asked to respond or designate a respondent to complete the survey. After the pilot, all other CSER U-award projects completed the survey in February/March 2016, for a total of nine completed surveys. Each site was subsequently asked to confirm the list of results returned to participants in Table 2; seven of nine sites made minor corrections.

Table 1 Conventional distinctions between research with human participants and clinical care of patients

\begin{tabular}{|c|c|c|}
\hline Areas of contrast & Research & Clinical care and laboratory practice \\
\hline Personnel & Investigator and participant & Clinician and patient \\
\hline Goals & Seek generalizable knowledge & Advance patient well-being \\
\hline Professionals' core duty & $\begin{array}{l}\text { Duty to conduct research in compliance with scientific and } \\
\text { ethical standards }\end{array}$ & Duty of clinical care in keeping with standards of care \\
\hline Key sources of standards & $\begin{array}{l}\text { Common Rule, FDA regulations on human subjects research, } \\
\text { Nuremberg Code, Declaration of Helsinki, CIOMS } \\
\text { Guidelines, Good Clinical Practice }\end{array}$ & $\begin{array}{l}\text { Established standards of care, clinical guidelines, clinical } \\
\text { laboratory standards (e.g., CLIA, state law), malpractice } \\
\text { adjudication }\end{array}$ \\
\hline Funding & Research grants and contracts, industry funding of research & $\begin{array}{l}\text { Payers including patients, insurers, state and federal } \\
\text { programs }\end{array}$ \\
\hline Records & Research records & Medical records \\
\hline
\end{tabular}

CIOMS, Council for International Organizations of Medical Sciences; CLIA, Clinical Laboratory Improvement Amendments; FDA, Food and Drug Administration; IRB, institutional review board; OHRP, Office for Human Research Protections. 
Table 2 Results returned in CSER U-award studies

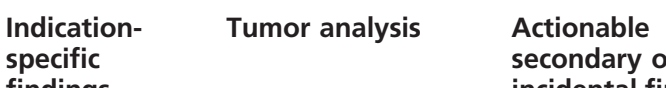

secondary or
incidental findings

Pharmacogenetic Carrier status Nonactionable

secondary or

incidental findings

VUS

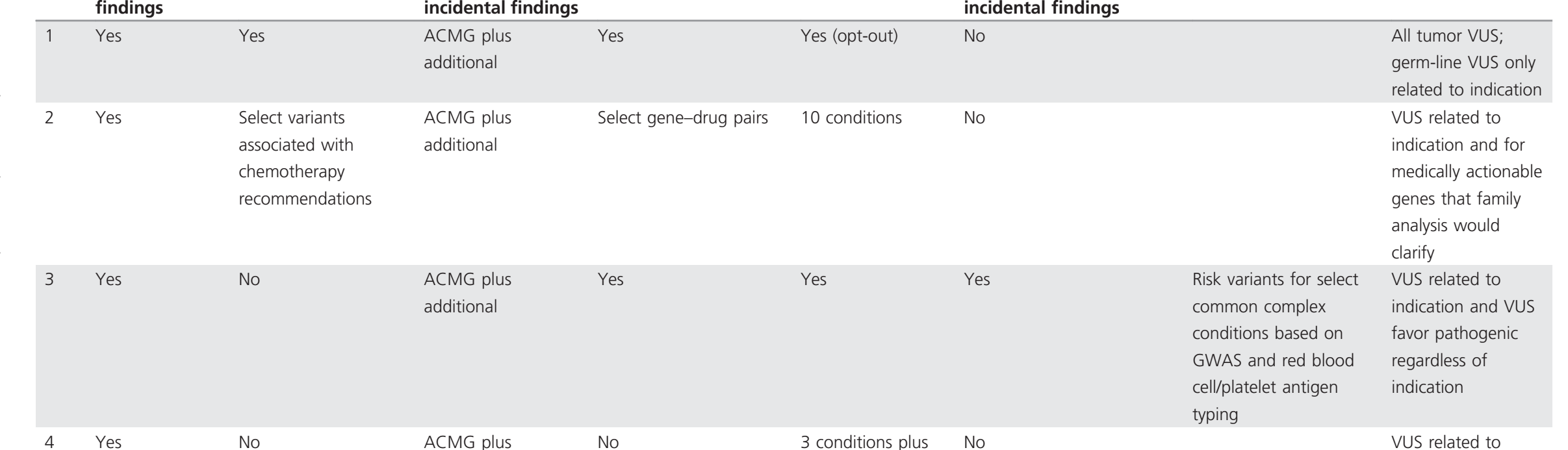

$4 \quad$ Yes

No

ACMG plus

No

3 conditions plus

No

OMIM genes for

indication

which participating

parents are both

\begin{tabular}{|c|c|c|c|c|c|c|c|c|}
\hline & & & & & & & & \\
\hline 5 & Yes & No & $\begin{array}{l}\text { Locally determined } \\
\text { list of actionable } \\
\text { conditions }\end{array}$ & Yes (opt-in) & Yes (opt-in) & $\begin{array}{l}\text { Yes (opt-in), including } \\
\text { rare but highly penetrant } \\
\text { variants for serious } \\
\text { nontreatable conditions }\end{array}$ & $\begin{array}{l}\text { Variants for risk in } \\
\text { select common complex } \\
\text { conditions based on } \\
\text { GWAS (opt-in) }\end{array}$ & $\begin{array}{l}\text { VUS related to } \\
\text { indication }\end{array}$ \\
\hline 6 & Yes & $\begin{array}{l}\text { Actionable or } \\
\text { potentially actionable } \\
\text { somatic variants with } \\
\text { focus on therapy }\end{array}$ & $\begin{array}{l}\text { ACMG plus } \\
\text { additional }\end{array}$ & No & Yes & No & & $\begin{array}{l}\text { VUS related to } \\
\text { indication }\end{array}$ \\
\hline 7 & Yes & No & $\begin{array}{l}\text { ACMG plus } \\
\text { additional (opt-in) }\end{array}$ & No & $\begin{array}{l}\text { Carrier status is } \\
\text { focus of study }\end{array}$ & No & $\begin{array}{l}\text { Variants in } \\
\text { mitochondrial genes }\end{array}$ & No \\
\hline 8 & Yes & Yes & $\begin{array}{l}\text { Custom list of } 2,000 \\
\text { plus genes }\end{array}$ & & Yes & No & & $\begin{array}{l}\text { VUS related to } \\
\text { indication }\end{array}$ \\
\hline 9 & Yes & Yes & Yes & No & No & No & & No \\
\hline
\end{tabular}

ACMG,

plus genes

No

No

No

"ACMG" refers to the roster of 56 secondary findings in Green et al. ${ }^{22}$ 


\section{Data analysis}

Descriptive data from 16 questions on specific components of the respondent's study design were compiled (by research coordinator Jeffrey $\mathrm{Ou}$ ) and analyzed by two working group members (S.M.W. and W.B.). Responses drawn primarily from six general questions about the research-clinical interface, but also from text responses to other questions, were analyzed qualitatively to ascertain how the research-clinical interface was described. Close reading of the text responses by three working group members (S.M.W., W.B., and G.E.H.) identified a continuum of characterizations of the researchclinical interface within the CSER studies, ranging from clear separation of research and clinical care activities to a full merger of the two. Four codes were defined representing points on the continuum: (1) clear separation of research and clinical activities; (2) interdigitation of the two, with steps taken to maintain the distinction; (3) a dynamic border between the two, subject to negotiation and case-bycase resolution; and (4) full merger. Two working group members (W.B. and J.H.-W.) coded the text responses independently. Coding disagreements were resolved by consensus.

\section{Informed consent}

\section{RESULTS}

Participants in all CSER projects signed informed consent forms for participation in the research. Some projects nonetheless reported participant confusion between research and clinical care:

We make a concerted effort to distinguish and separate these [research and clinical care] activities in our description of study participation during the informed consent conversation as well as through the consent document, however clearly some confusion remains.... [Site 2]

Our subjects frequently complete multiple consents including treatment trials as well as consent for procedures, bone marrow biopsies, surgeries at the same time. I think that [they] can get confused among the studies or the differences between pure research and pure clinical. [Site 1]

Some studies, however, reported that participants had limited or no confusion between research and clinical care:

It seems generally clear to our participants that they're engaged in research that might have clinical Implications [sic]. This is the norm in clinical research. I think that our lack of problems has been facilitated, in part, by having a physically separate area in which participants are consented and in which results are returned. In addition, we take care to distinguish the research-generated results from the clinically confirmed results and also make this distinction in the informed consent session. [Site 5]
In keeping with this response, five of the nine projects reported that they utilized research space or a separate visit to complete the research consent procedures.

The consent takes place in research space and is prior to the delivery of care. [Site 3]

\section{Clinician and researcher roles}

Clinicians participated in study design in eight of nine studies, provided results to participants in all studies, and delivered care following research testing in four of nine studies. Eight of nine studies also involved some enrollment of clinicians as participants, with interviews of referring clinicians or observation of clinician decision-making following testing. For six of the nine studies, at least some of the research procedures occurred in clinical settings, for example obtaining samples for research-related testing concurrent with delivery of clinical care.

Role ambiguity was noted in six of nine studies. This is due in part to the fact that some personnel have both clinical care and research roles, and may find it challenging to navigate between the two. One study reported:

[W] have intentionally chosen to "hand off" patient management to the clinical care team following results disclosure by the research team. Sometimes it is difficult to draw this line distinctly because the care is being handedoff from one genetic counselor (in research setting) to a different genetic counselor (in clinical setting), and the genetic counselors on the study team have these same roles as part of the clinical team on different days of the weekand, in fact, could be the provider that the patient is referred to. [Site 7]

However, some studies did not find significant confusion about the roles played by research and clinical personnel:

[W] have not experienced ambiguity for issues like families asking the research team questions they should be asking their provider. [Site 4]

\section{Disclosure of primary results and secondary findings}

The projects varied in the categories of results disclosed to participants (Table 2). All projects disclosed results related to the clinical indication for which the participant was enrolled and most also returned variants of uncertain significance that were related to the clinical indication. All returned medically actionable secondary (or incidental) findings as well, usually a list generated by the study team that included some or all of the 56 genes recommended by the American College of Medical Genetics and Genomics in 2013 for return of secondary findings in clinical sequencing $^{22}$ (a list revised in 2016), ${ }^{23}$ plus additional genes determined to generate actionable medical findings. ${ }^{4}$ Each of the projects also returned different combinations of further genomic findings. Projects reported differing 
strategies for navigating the research-clinical interface in results disclosure:

Provider participants decided if they wanted to see their patients for the results disclosure session in research space or in their clinical space as part of a regular clinical appointment. Most of the results disclosure visits occurred as part of a clinical visit in the clinical space, but a few were scheduled on a case-by-case basis in the research space. [Site 3]

Participants are returned research results by research personnel - study genetic counselor [sic] and, when necessary/available an MD clinical geneticist. [Site 2]

\section{Placement of results in the medical record}

Projects varied in placement of study results in the medical record. Five projects placed all research results in the medical record; two projects placed only selected results. One project noted that primary findings related to the participant's medical indication would be placed in the medical record if requested by the participating family. Another project sought specific consent from participants for the placement of diagnostic or medically actionable research findings in the medical record. One project noted:

Since our results are all placed in the medical record and the information is used by their clinicians there is heavy overlap [between research and clinical]. [Site 1]

\section{Payment for services}

The question of what services should be billed to the research study versus insurers and clinical payers was confusing to some participants:

Participants have expressed confusion regarding what testing is billed to their insurance and what testing is being covered by the research study and some seem not to realize that two tests are being done. [Site 2]

Respondents reported circumstances in which funding was split, such as when clinical payers declined payment leading the research team to fund a test instead. Thus, some projects responded to payer decisions or negotiated, in a dynamic resolution of whether research or clinical funding would cover the cost:

Any downstream care as a result of the research is clinical care.... If a pregnant woman and her partner are found to be a carrier of the same condition, additional testing like amniocentesis or [chorionic villus sampling] would be part of her medical benefits. The study had thought expedited partner testing due to a pregnancy would be clinical care, but the insurer disagreed that expedited partner testing should be a covered benefit. Thus, expedited partner testing is now part of the research activities. [Site 7]

\section{Legal, regulatory, and ethical issues considered}

The survey respondents were queried about any legal issues considered in the design or implementation of their CSER project. A recurring issue was determining whether results returned to participants had to originate from a CLIAcertified laboratory. Three studies utilized a research laboratory, with CLIA laboratory confirmation of any results returned to participants. One study developed a CLIAcertified laboratory to handle research assays during the course of the study. The remaining five studies utilized a CLIA-certified laboratory throughout the study.

However, one respondent noted:

The return of non-CLIA data continues to be a HUGE issue. I think that ethically it is clear that subjects/parents want research data, I think they have a right to it and in particular the fact that some IRB's [sic] absolutely refuse disclosure and others allow it makes the situation, particularly for a multi-institutional study, extremely difficult. [Site 1]

One study reported a request from a participating family for raw genomic data from the study. Researchers complied with the request because of 2014 regulatory revisions allowing

Table 3 Characterizations of the research-clinical interface Characterization of interface

1. Research and clinical care seen as distinct
2. Research and clinical care seen as distinct but
interdigitated

interdigitated Explication Research components are clearly designated and differentiated from clinical care (e.g., consent for participation is sought by research personnel in space dedicated to research) Despite differentiation between research and clinical care in study design, the mixing of research and clinical care leads to potential confusion, prompting efforts to distinguish the two domains (e.g., avoiding having the clinician seek research consent; research team intentionally chooses to "hand off" management to clinical team after return of research results)

\section{Negotiated or dynamically evolving interface} between research and clinical care

4. Translational merger of research and clinical care Decisions related to research and clinical care activities are made in a negotiated or dynamically evolving way (e.g., determining which results to disclose to a participant or whether the research budget will cover costs of testing)

Research and clinical care cannot be separated (e.g., study results are used to direct clinical care)

Bolded selected words signify differences among the 4 characterizations. 
Table 4 Summary of coding distribution for text responses to survey questions across 4 characterizations of the research-clinical interface, by site

\begin{tabular}{|c|c|c|c|c|}
\hline Site & $\begin{array}{c}\text { (1) } \\
\text { Distinct }\end{array}$ & $\begin{array}{c}\text { (2) } \\
\text { Interdigitated }\end{array}$ & $\begin{array}{c}(3) \\
\text { Dynamically } \\
\text { evolving }\end{array}$ & $\begin{array}{l}(4) \\
\text { Merger }\end{array}$ \\
\hline 1 & $X$ & $x$ & $x$ & $x$ \\
\hline 2 & $x$ & $X$ & $x$ & $x$ \\
\hline 3 & $x$ & $x$ & $x$ & $x$ \\
\hline 4 & $x$ & $x$ & $x$ & $x$ \\
\hline 5 & $x$ & $x$ & & \\
\hline 6 & $X$ & $x$ & $X$ & $X$ \\
\hline 7 & $x$ & $x$ & $x$ & \\
\hline 8 & $x$ & $x$ & & $X$ \\
\hline 9 & $X$ & $X$ & $X$ & \\
\hline
\end{tabular}

" $X$ " indicates at least one response corresponding to the characterization indicated.

patients direct access to laboratory findings, ${ }^{24}$ but asked the family to sign a waiver and pay for the costs of transmission.

Two studies noted discussion of potential malpractice concerns, one related to return of results, the other to potential difficulties in accessing follow-up clinical care. One study reported developing a form to allow participants to designate a recipient for their test results if the participant died before receiving results. One study noted lengthy discussion about the return of information concerning adult-onset disorders to its pediatric population.

\section{Characterizations of the research-clinical interface}

Analysis of our survey responses suggests four characterizations of the research-clinical care interface in translational research, arrayed along a continuum. These characterizations range from the view that research and clinical care are fully distinct to the view that research and clinical are fully merged (displayed in Table 3).

As depicted in Table 4, all CSER sites deployed at least two characterizations. Responses from all sites included answers recognizing the distinction between research and clinical care (characterization 1), and described steps taken to reinforce the difference between research and clinical care in the face of potential confusion (characterization 2). However, the majority of sites also submitted responses characterizing the research-clinical interface as dynamic or the two spheres as merged. Seven of nine sites revealed a process involving dynamic negotiation to determine whether a process (such as payment for testing or follow-up) would be considered research or clinical care (characterization 3 ), and six of nine sites offered responses that characterized research and clinical care as merged rather than separate spheres (characterization 4). The four characterizations are further described below.

Clear distinction between research and clinical care (characterization 1). At one end of the continuum, the distinction between research and clinical care is readily apparent. For example, CSER studies sometimes enroll patients referred by a different clinical institution, allowing for a clear separation of research activities from clinical care. All CSER studies include informed consent for research procedures, and these are specified in research protocols.

Interdigitation of research and clinical care, with steps taken to maintain the distinction (characterization 2). In many instances, however, research and clinical activities occur in the same location or are administered by personnel who have both clinical and research roles. In these settings, responses to several questions noted an obligation on the part of researchers to clearly communicate differences between research and clinical care. Thus, researchers in several CSER studies chose to conduct informed consent or other research procedures in a dedicated research space, or limit research activities of clinicians, to help participants to distinguish research activities from clinical care.

In contrast to the first two characterizations, which treat research and clinical care as separate spheres and take steps to maintain the distinction, the third and fourth characterizations reject a strict separation. Instead, they treat the relationship between research and clinical care as a dynamically evolving interface on a case-by-case basis or treat the two domains as merged.

Negotiated or dynamically evolving interface (characterization 3). Some survey responses revealed case-by-case decision-making in which processes may be characterized as either clinical or research based on negotiation and dynamic response to events. In one study, a variant review committee had been established to determine which research results would be disclosed to participants; however, treating clinicians retained the right and responsibility to make the final decision about which variants were disclosed. Another study established a research fund that could reimburse participants if insurance coverage was not available for tests needed to qualify for study participation.

Translational merger of research and clinical care (characterization 4). At the other end of the continuum, a number of survey responses noted that research and clinical care are merging and rejected the idea that these are separate spheres. CSER research provides clinical benefit to at least some participants by generating information that can be used in clinical care. At the same time, sequencing can produce new genomic discoveries prompting further research. Several respondents reflected on the merger of research and clinical care:

We believe [the CSER studies] are intrinsically both [research and clinical care]. Given the nature of the data generation and analysis process and the regular rates of change in genome interpretation, each family is in a very real sense a research project. However, the consequences of the results are often of substantial and direct clinical impact, and thereby these efforts are also clinical care. [Site 4]

...I think [the distinction between research and clinical care] is a false dichotomy. [Site 1] 
Respondents also noted that blending of research and clinical care stems in part from the state of genomic science.

Because we still do not understand penetrance in the genomic space, we do not know what clinical recommendations should be made as the result of variants detected by a CLIA approved research study, the line between what is "investigational" vs what is true clinical care is still blurred. [Site 3]

The entire field of genomic diagnostics has been operating on the research/clinical interface, in that our procedures and knowledge are constantly evolving. While in some sense this is a problem, it is what has been pushing the field forward. [Site 8]

\section{DISCUSSION}

CSER investigators report a range of experiences in navigating the research-clinical interface. The question of how to conceptualize, plan for, and deal with this interface appears to arise in multiple contexts, from design of the study through execution and follow-up. CSER approaches to these issues appear to reflect a community of genomics investigators addressing multiple challenges at the research-clinical interface.

\section{Continuum of characterizations}

Our results also revealed four characterizations of the research-clinical interface as summarized in Table 3. These ranged from the traditional, dichotomous view of two separate spheres to the view that research and clinical care are fully merged in CSER projects, which raises a number of important questions. Different characterizations occurred in answers from each study, with all studies including at least two of the four.

The first question is why we see these four ways of thinking about the research-clinical interface, instead of just one way. The range of characterizations - and especially the third and fourth ones, rejecting a fixed boundary between research and clinical care-may suggest that we are seeing the emergence of a translational research perspective that focuses on how best to make the transition from the bench to the bedside. A number of authors have called for the development of a more translational approach to research ethics that deals explicitly with increasingly blended approaches to research and clinical care without losing sight of protections needed for research participants. $1,25,26$

Finally, the continuum evident in these survey responses invites consideration of whether current translational genomics research, especially involving indication-based sequencing in patients with suspected genetic conditions, makes research and clinical care difficult to differentiate. While blending of the two activities occurs in much clinical research, it is likely to be most evident for emerging technologies with the potential to yield clear benefit for some participants but not all, leading to uncertainty about optimal use and justifying research. The definitive diagnosis or clear treatment guidance produced for some CSER participants exemplifies why research and clinical care are difficult to separate. Sequencing can also generate genomic discovery and new research questions. Thus, translational genomics powers both clinical integration and further research. 1,27

Examination of how investigators view the research-clinical interface in genomic research beyond CSER studies and in realms of translational research beyond genomics would be illuminating. The larger genomics research community may show even greater diversity in approach. Beyond genomics, a blurred interface may characterize any clinical research involving interventions showing clear benefit for some patients but requiring additional research to clarify benefits, harms, and best practices for clinical integration.

\section{Practical implications}

The fact that six of the nine CSER studies described a merger of research and clinical care, at least in response to some survey questions (see Table 4), raises important questions about the conduct of such translational genomics studies. First, this perceived merger challenges the conventional wisdom that investigators should emphasize that research differs from clinical care, as research seeks generalizable knowledge, while the sole aim of clinical care is to advance each patient's welfare. The conventional dichotomy of research and clinical care also creates contrasting requirements for research versus clinical consent, questions concerning use of a clinical versus research laboratory, and decisions about whether to record results in the research or clinical record. In CSER studies striving to establish the clinical utility of sequencing and determine how best to integrate sequencing into clinical care, the traditional dichotomy between research and clinical care may be difficult to apply.

Second, in the context of CSER studies, disclosing results serves multiple purposes-advancing knowledge on how to communicate findings and sharing results that may have direct clinical relevance. In this context, the issue is not so much the sometimes-debated question of whether returning research results conflates research with clinical care, as it is what scope of findings should be returned. Should disclosure stop with findings that are well understood and clinically significant, or include more uncertain results? Individual research projects may set the scope of return differently. ${ }^{19}$

Third, is the IRB - an oversight body for research — the right body to oversee what results are returned in these studies for the purposes of clinical care? The results may originate in research studies, but the questions raised by patient access to and clinical use of well-validated and clinically significant results from a CLIA-certified lab go beyond research design, and even the ancillary care obligations of investigators, ${ }^{28}$ to questions of appropriate clinical care. It may be useful to turn to specialized bodies such as Informed Cohort Oversight Boards dedicated to handling return-of-results questions to augment IRB oversight of research procedures. ${ }^{29,30}$

Finally, does translational merger of research and clinical care have implications for insurance coverage and malpractice 
liability exposure? Both customarily attach only in domains of clinical care. Yet the rapid progress of genomics in establishing the significance of genomic variants in diagnosis and care $^{31,32}$ suggests that new mechanisms are needed to support patient access while creating appropriate expectations for responsible clinical implementation. ${ }^{33}$

\section{Limitations}

This analysis is based on survey responses from nine studies, all of which participate in the CSER Consortium. Although these studies were designed independently and survey responses indicate a range of perspectives, the consortium has served as a platform for collaboration. Thus, a survey extending beyond the consortium might reveal a wider range of views. In addition, the survey considered only projects focusing on genome and exome sequencing. Comparison to the views of investigators navigating the research-clinical interface in other domains of translational research is an essential next step.

\section{Conclusion}

Surveying investigators on the cutting edge of genomics implementation reveals challenges at the research-clinical interface, as well as a range of strategies for meeting those challenges. More importantly, analysis of how these investigators characterize that interface suggests that the traditional dichotomous approach is now part of a broader continuum of perspectives including merger of research and clinical care. This poses fundamental challenges to the conduct, ethics, and oversight of both research and clinical care in translational genomics.

\section{SUPPLEMENTARY MATERIAL}

Supplementary material is linked to the online version of the paper at http://www.nature.com/gim

\section{ACKNOWLEDGMENTS}

Preparation of this article was supported by the following grants from the National Institutes of Health (NIH): U01HG006507, U01H007307, R01CA154517, R01HG008605, R01HG006600, R21HG00612, U01HG006487, P2OHG007243, U01HG006485, and U01HG006500. This research was also supported by the Actionability and Return of Results Working Group of the Clinical Sequencing Exploratory Research (CSER) Consortium, which is funded by the National Human Genome Research Institute (NHGRI) and National Cancer Institute (NCI). Thanks to Jeffrey Ou for assistance in compiling data and to Laura Rodriguez for helpful comments. The views expressed in this article are those of the authors and do not necessarily reflect those of the $\mathrm{NIH}, \mathrm{NHGRI}, \mathrm{NCl}$, or the CSER Consortium.

\section{DISCLOSURE}

Robert Green receives compensation for speaking or consultation to AIA, GenePeeks, Helix, Illumina, Ohana, Prudential, and Veritas, and is co-founder and advisor to Genome Medical, Inc. Pearl O'Rourke is on a Bioethics Advisory Committee for Takeda.

\section{REFERENCES}

1. Wolf SM, Burke W, Koenig BA. Mapping the ethics of translational genomics: situating return of results and navigating the researchclinical divide. J Law Med Ethics 2015;43:486-501.

2. Green RC, Goddard KAB, Jarvik GP, et al. The Clinical Sequencing Exploratory Research Consortium: accelerating the evidence-based practice of genomic medicine. Am J Hum Genet 2016;98:1051-1066.

3. National Institutes of Health. RFA-HG-10-017: Clinical Sequencing Exploratory Research (U01). https://grants.nih.gov/grants/guide/rfa-files/ RFA-HG-10-017.html. Accessed 12 March 2017.

4. Berg J, Amendola LM, Eng C, et al. Processes and preliminary outputs for identification of actionable genes as incidental findings in genomic sequence data in the Clinical Sequencing Exploratory Research Consortium. Genet Med 2013;15:860-867.

5. Henderson GE, Wolf SM, Kuczynski KJ, et al. The challenge of informed consent and return of results in translational genomics: empirical analysis and recommendations. J Law Med Ethics 2014;42:344-355.

6. Easter MM, Henderson GE, Davis AM, Churchill LR, King NMP. The many meanings of care in clinical research. Sociol Health IIIness 2006;28:695-712.

7. Largent EA, Joffe S, Miller FG. Can research and care be ethically integrated? Hastings Cent Rep 2011;41(4):37-46.

8. Wolf SM. Return of individual research results and incidental findings: facing the challenges of translational science. Annu Rev Genomics Hum Genet 2013;14:557-577.

9. Hall A, Alberg C, Luheshi L. PHG Foundation. Genomics and the boundary between research and clinical care and treatment. 2014. http:// www.phgfoundation.org/briefing_notes/303/. Accessed 30 January 2017.

10. Angrist $M$, Jamal L. Living laboratory: whole-genome sequencing as a learning healthcare enterprise. Clin Genet 2015;87:311-318. Accessed on August 2017.

11. National Commission for the Protection of Human Subjects of Biomedical and Behavioral Research. The Belmont Report. 1979. https://www.hhs. gov/ohrp/regulations-and-policy/belmont-report/index.html. Accessed 18 August 2017.

12. Office for Human Research Protections (OHRP). Federal policy for the protection of human subjects ('Common Rule'). 2016. https://www.hhs. gov/ohrp/regulations-and-policy/regulations/common-rule/. Accessed 18 August 2017

13. US Department of Homeland Security, Department of Agriculture, Department of Energy, et al. Federal policy for the protection of human subjects. Fed Regist 2017;82:7149-7274.

14. Beauchamp TL, Saghai $Y$. The historical foundations of the researchpractice distinction in bioethics. Theor Med Bioeth 2012;33:45-56.

15. Henderson GE, Churchill LR, Davis AM, et al. Clinical trials and medical care: defining the therapeutic misconception. PLoS Med 2007:4:e324.

16. Phimister EG, Feero WG, Guttmacher AE. Realizing genomic medicine. $N$ Engl J Med 2012;366:757-759.

17. Brody $\mathrm{H}$, Miller FG. The research-clinical practice distinction, learning health systems, and relationships. Hastings Cent Rep 2013;43(5):41-47.

18. Burke W, Evans BJ, Jarvik GP. Return of results: ethical and legal distinctions between research and clinical care. Am J Med Genet C Semin Med Genet 2014;166C:105-111.

19. Jarvik GP, Amendola LM, Berg JS, et al. Return of results to research participants: the floor, the ceiling, and the choices in between. Am J Hum Genet 2014;94:818-826.

20. Berkman BE, Hull S, Eckstein LG. The unintended implications of blurring the line between research and clinical care in a genomic age. Per Med 2014;11:1-18.

21. Lee SS, Kelley M, Cho MK, et al. Adrift in the gray zone: IRB perspectives on research in the learning health system. AJOB Empir Bioeth 2016;7: 125-134.

22. Green RC, Berg JS, Grody WW, et al. ACMG recommendations for reporting of incidental findings in clinical exome and genome sequencing. Genet Med 2013;15:565-574.

23. Kalia SS, Adelman K, Bale SJ, et al. Recommendations for reporting of secondary findings in clinical exome and genome sequencing, 2016 update (ACMG SF v2.0): a policy statement of the American College of Medical Genetics and Genomics. Genet Med 2016;19:249-255.

24. Evans BJ, Dorschner MO, Burke W, Jarvik GP. Regulatory changes raise troubling questions for genomic testing. Genet Med 2014;16: 799-803.

25. Kelley M, Edwards K, Starks H, et al. Values in translation: how asking the right questions can move translational science toward greater health impact. Clin Trans/ Sci 2012;5:445-451. 
26. Faden RR, Kass NE, Goodman SN, Pronovost P, Tunis S, Beauchamp TL. An ethics framework for a learning health care system: a departure from traditional research ethics and clinical ethics. Hastings Cent Rep 2013;43 (1):S16-S27.

27. Biesecker LG. Incidental variants are critical for genomics. Am J Hum Genet 2013;92:648-651.

28. Richardson HS, Belsky L. The ancillary-care responsibilities of medical researchers: an ethical framework for thinking about the clinical care that researchers owe their subjects. Hastings Cent Rep 2004;34(1):25-33.

29. Kohane IS, Mandl KD, Taylor PL, Holm IA, Nigrin DJ, Kunkel LM. Reestablishing the researcher-patient compact. Science 2007;316: 836-837.

30. Holm IA, Savage SK, Green RC, et al. Guidelines for return of results from pediatric genomic studies: deliberations of the Boston Children's Hospital Gene Partnership Informed Cohort Oversight Board. Genet Med 2014;16:547-552.

31. Evans JP, Khoury MJ. The arrival of genomic medicine to the clinic is only the beginning of the journey. Genet Med 2013;15:268-269.

32. Manolio TA, Chisholm RL, Ozenberger B, et al. Implementing genomic medicine in the clinic: the future is here. Genet Med 2013;15:258-267.
33. Marchant GE, Scheckel K, Campos-Outcalt D. Contrasting medical and legal standards of evidence: a precision medicine case study. J Law Med Ethics 2016;44:194-204.

(i) (2) $($ This work is licensed under a Creative Commons Attribution-NonCommercial-NoDerivs

International License. The images or other third party material in this article are included in the article's Creative Commons license, unless indicated otherwise in the credit line; if the material is not included under the Creative Commons license, users will need to obtain permission from the license holder to reproduce the material. To view a copy of this license, visit http://creativecommons.org/licenses/ by-nc-nd/4.0/

(c) The Author(s) 2018 